\title{
An Ergonomics Assessment of Three Simulated 120 m Ladder Ascents: A comparison of Novice and Experience Climbers
}

Gemma S. Milligan, Joseph O'Halloran \& Michael J. Tipton

\begin{abstract}
This study investigated the ergonomics of three simulated $120 \mathrm{~m}$ vertical ladder ascents and differences between novice (NC) and experienced climbers (EC). Seven EC and 10 NC undertook three $120 \mathrm{~m}$ climbs; comprising of four $30 \mathrm{~m}$ climbs. Ascending $120 \mathrm{~m}$ was reported as a high physical demand, supported by high peak HRs $\left(\sim 173 \mathrm{~b} \cdot \mathrm{min}^{-1}\right.$ across the three climbs) and ${ }^{\cdot} \mathrm{O}_{2}\left(\sim 3.1 \mathrm{~L} \cdot \mathrm{min}^{-1}\right.$ across the three climbs $)$. Grip strength and endurance were significantly $(\mathrm{p}<0.05)$ impaired by ascents. With multiple ascents, toe clearance was reduced (Climb $1-0.0515 \mathrm{~m}$; Climb $3-0.046 \mathrm{~m})$, andapticipants reached higher with their arms (shoulder angle: Climb $1-117^{\circ}$; Climb $3-136^{\circ}$ ). NC demonstrated less range of movement through the hips $\left(\mathrm{NC}-46^{\circ} ; \mathrm{EC}-58^{\circ}\right)$, and higher muscle activation in the upper body $(\mathrm{NC}-$ $60 \%$; EC - 49\%). Experience reduced cumulative climbing times (exercise + rest), whilst maintaining the same physiological demand as NC and maintained optimised movement patterns for longer.
\end{abstract}

Keywords: Wind Turbine; Ladder Climbing; Offshore Wind Industry 


\subsection{Introduction}

The Offshore Wind Industry (OWI) has seen large-scale commercial development since 1993 (Henderson et al, 2003). Operational turbines require service and maintenance by technicians who are typically required to undertake the: testing of mechanical, hydraulic and electrical components and systems; inspection of physical integrity of towers; climbing of towers to inspect or repair turbine equipment; collection of turbine data for testing or research and analysis; performance of routine maintenance on wind turbine; and troubleshooting mechanical, hydraulic, or electrical malfunctions. With the introduction of large scale operations, the ergonomic demands placed on the technicians working on the turbines should be quantified. The first step in determining the requirements of technicians is to conduct a critical task analysis to identify those jobs which a high physical demand (Tipton et al, 2013). A critical task analysis determined climbing vertical ladders to be one of five critical tasks for technicians working in the Offshore Wind Industry (OWI) (Milligan et al, 2019). This analysis determined that technicians of the OWI could be required to climb distances ranging between $80 \mathrm{~m}$ to $120 \mathrm{~m}$, made up of several ladders, approximately 3 times a day. Subject Matter Experts of the OWI report there are no time constraints placed on a technicians ascending the turbine, with the opportunity to rest at any point (Milligan et al, 2019 in publication).

Ladder climbing is a generic task that is common in a number of occupations. However, there is no literature available that details the physiological demands of prolonged ladder climbing (i.e. greater than $80 \mathrm{~m}$ ). Most ladder climbing research has been completed either on short fixed vertical ladders (e.g. Gledhill \& Jamnik, 1992; Milligan, 2013) or on pitched ladders (Kamon, 1970; Kamon \& Pandolf, 1972; Kamon et al, 1973). One study undertaken on short fixed vertical ladders reported an aerobic demand $\left(\dot{V} \mathrm{O}_{2}\right)$ of: $8.8(2.2) \mathrm{mL} \cdot \mathrm{kg}^{-1} \cdot \mathrm{min}^{-1}$ at a speed of 17 rungs. $\mathrm{min}^{-1}$ increasing to $23.6(2.8) \mathrm{mL} \cdot \mathrm{kg}^{-1} \cdot \mathrm{min}^{-1}$ at 24 rungs. $\mathrm{min}^{-1}$ and $28.9(3.4) \mathrm{mL} \cdot \mathrm{kg}^{-1} \cdot \mathrm{min}^{-}$

${ }^{1}$ at 34.5 rungs.min ${ }^{-1}$, to ascend and descend a static $3 \mathrm{~m}$ ladder, continuously for 3 minutes. 
Mean (SD) HR was reported to be 144 (18.6) b. $\mathrm{min}^{-1}$ at 17 rungs.min ${ }^{-1}, 135$ (22.6) b. min $^{-1}$ at 24 rungs. $\mathrm{min}^{-1}$ and 147 (19.7) b. $\mathrm{min}^{-1}$ at 34.5 rungs. $\mathrm{min}^{-1}$ (Milligan, 2013). Yet, the use of short ladders, which require the participants to repeatedly ascend and descend, have been shown to reduce the physical demand when compared to ascending alone. Kamon (1970) found a $26 \%$ decrease in $\dot{V} \mathrm{O}_{2}$ when descending a ladder ergometer compared to ascending. Barron et al. (2017) observed a much greater decrease of $46 \%\left(28.3[3.5] \mathrm{mL} \cdot \mathrm{kg}^{-1} \cdot \mathrm{min}^{-1}\right.$ to 15.3 [3.7] mL.kg${ }^{1} \cdot \mathrm{min}^{-1}$ ) in $\dot{V} \mathrm{O}_{2}$ during a single $3 \mathrm{~min} 45 \mathrm{sec}$ ascent compared to descending a $30 \mathrm{~m}$ vertical ladder. This is most likely due to the partial recovery participants can expect during descending which has a lower physiological demand (Kamon, 1970).

The pitch of the ladder has important implications in terms of the physical demand placed on climbers. Significant differences between both energy expenditure (11.4 kcal.min ${ }^{-1}$ v. 13.1 kcal.min ${ }^{-1}$ ) and mean HR (142 b. in $^{-1}$ v. 155 b. $\mathrm{min}^{-1}$ ) have been observed when climbing at $75^{\circ}$ and $90^{\circ}$ respectively (Vi, 2008). Barron et al. (2018) reported a $17.3 \%$ and $15.8 \%$ increase in $\dot{V} \mathrm{O}_{2}$ and heart rate respectively, when climbing a vertical ladder compared to a pitched ladder of $75^{\circ}$, at three speeds. Leaning forward onto a $75^{\circ}$ ladder allows the centre of mass to move over the base of support at the feet, making the task easier (Vi, 2008).

Maximum grip strength has been measured before and immediately after climbing a vertical ladder for 3 minutes; the data showed decrements in maximum grip strength of $17.8 \%$ (left hand) and $15.5 \%$ (right hand) when ascending and descending a 3 m ladder at 34.5 rungs.min ${ }^{-}$ ${ }^{1}$ (Milligan, 2013). Whilst a continuous climb to of $80 \mathrm{~m}$ demonstrated $21 \%$ to $25 \%$ loss in grip strength and a tendency towards a loss of fine motor control (Stewart \& Mitchell, 2018). These are similar to the values reported in previous research, such as decrements in maximum grip strength of $20 \%$ following a stretcher-carrying task resulting in poorer performance of fine motor skills (Leyk et al, 2006). These performance decrements were not observed when maximum grip strength was reported to be reduced by $12 \%$ or less (Leyk et al, 2006). 
The biomechanical aspects of ladder climbing have received very little attention. Much of the ladder-related literature has emphasised the prevention of injury, particularly in relation to slipping (Pliner et al, 2014; Pliner et al, 2015; Pliner \& Beschomer, 2017; Pliner et al, 2017). Foot positions (restricted toe clearance vs. unrestricted) and hand positions (rungs vs. rails) were examined in relation to recovery from slipping (Pliner et al, 2014). Slipping was six times more likely $(p<0.01)$ with restricted toe clearance than with unrestricted. Maintaining sufficient toe clearance may reduce ladder falls, however, no value was placed on what constitutes a minimum acceptable requirement for toe clearance (Pliner et al, 2014). Grasping the ladder rungs was found to provide a better grip, thus reducing the likelihood of a slip and preventing a fall (Barnett \& Poczynck, 2000; Young et al, 2009; Pliner et al, 2014).

Pliner (2017) found that there does not seem to be a preferred climbing pattern during ladder ascent, agreeing with findings by McIntrye (1983). During ladder descent, 4-beat, lateral climbing was used the most, partially contradicting findings by Hammer and Schmalz (1992), who reported 2-beat, lateral climbing to be used the most during descent. Some evidence suggests that the more climbing an individual does, the stronger the preference for an individualised climbing gait (McIntyre, 1983). Although previous studies (e.g. Hammer and Schmalz, 1992) suggested that certain climbing patterns are safer, Pliner et al. (2017) concluded that they could not suggest a specific climbing pattern to improve recovery with a ladder after a perturbation (use of a step that slipped away from under the participant). Schorenburg et al. (2015) have shown that climbing style does not impact on fall severity after slipping. Notwithstanding these studies, there is no further recent information to guide limb movements or the impact that experience has on ladder climbing technique. From the experimental research, the feet are the primary load-bearing interface during ladder climbing, while the hands are largely responsible for balancing the body during climbing and for recovery 
after a slip or trip (Armstrong et al, 2009). Holding the rails instead of the rungs does result in lower hand forces but increases the instability of the body (Armstrong et al, 2009). Foot forces measured during climbing have varied between $55 \%$ (Bloswick \& Chaffin, 1990) and $96 \%$ (Armstrong et al, 2009) of a climber's bodyweight. Although the total force applied is speedspecific, relatively measured the force increases as time into the climb increases indicating greater acceleration of the limbs with less control of the limb as it makes contact with the rung. Although this is useful in understanding the force exerted during short distance climbing, the extant knowledge cannot inform the effect of the demands of work now being done in large offshore turbines. This required context specific work using vertical ladder ergometers to examine the biomechanics of long term climbing.

The ecological relevance of the ladder climbing literature is limited as ladder climbing research has been conducted either on short ladders involving multiple ascents and descent or, alternatively, using a non-vertical ladder. Most literature reported focuses on healthy populations with no previous ladder climbing experience (Milligan, 2013; Barron et al, 2018). The extant knowledge cannot inform the effect of the demands of work now being done in large offshore turbines, hence justifying context specific work using vertical ladder ergometers. Therefore the primary aim of this study was to understand the ergonomics placed on Technicians during prolonged ladder climbing over the working day. The secondary aim of this study was to compare novice (NC) to experienced climbers (EC). It was hypothesised there would be no significant differences in physical and biomechanical factors between climbs 1 , and 2; 1 and 3; and 2 and 3 and there would be no significant differences in physical and biomechanical factors between NC and EC.

\subsection{Methods}


The study was given favourable ethical opinion by the Science Faculty Research Degrees Committee at the University of Portsmouth.

\subsection{Participants}

Based on a power calculation (power set to 0.8 and a medium effect size [G*Power 3.1, Dusseldorf]), seventeen participants $(3=$ female; $14=$ male) were tested (Table 1$)$. Of these seven were EC from the OWI $(2=$ female; $5=$ male; Table 1$)$ and 10 were NC $(1=$ female; 9 $=$ male; Table 1). All participants were provided with a full written and verbal brief, prior to providing written consent.

INSERT TABLE 1 HERE

\subsection{Procedures}

Upon arrival participants were familiarised (first shown then given time to practice) with the ladder ergometer (HP Cosmos, Germany). Speed was dictated in terms of rung.min ${ }^{-1}$, based on the following ladder dimensions: height of climb: $235 \mathrm{~cm}$ max; rung interval: $24.4 \mathrm{~cm}$ (10 inch) and rung width: $49.5 \mathrm{~cm}$ (20 inch). Additionally the ladder ergometer was modified to vertical from the factory standard $75^{\circ}$ to $90^{\circ}$ (Figure 1 ).

\section{INSERT FIGURE 1 HERE}

Participants' stature to the nearest $0.1 \mathrm{~cm}$, mass to the nearest $0.05 \mathrm{~kg}$ (Model B150S Sartorious, UK) were measured in minimal standard clothing (shorts and T-shirt, and socks without shoes). Skinfold thickness from eight sites (triceps, subscapular, biceps, iliac crest, supraspinale, abdominal, front thigh, medial calf) were measured using the guidelines provided 
by the International Society for the Advancement of Kinanthropometry (ISAK, Stewart et al, 2011), prior to undertaking the Chester Step test (Sykes \& Roberts, 2004). Following this, participants donned $6.5 \mathrm{~kg}$ of Personal Protective Equipment (PPE) including: work overalls, steel toe-capped boots, a full climbing harness and accessories, helmet and gloves (NB. For the first trial only EC were asked to don an additional $2.3 \mathrm{~kg}$ of PPE including a sea survival suit and lifejacket, this was part of another aspect of the study that is not reported here). EMG electrodes were placed on the shoulder, upper arm, forearm and calf to measure muscle activity, and kinematic markers placed on the body. Participants were required to rest seated for 5 minutes to allow for a resting blood lactate (BLa, Lactate Plus, Lactate Meter, Nova Biomedical, USA), from the earlobe, to be taken. Maximum grip strength and $30 \mathrm{~s}$ grip endurance were measured using a Precision Dynamometer G100 (Biometrics Ltd, Gwent, UK).

Each participant undertook three simulated $120 \mathrm{~m}$ ladder climbs. Each simulated $120 \mathrm{~m}$ climb was split into four $30 \mathrm{~m}$ climbs with a climb:rest ratio of 1:1, i.e. the time taken to climb $30 \mathrm{~m}$ was used as the time of the subsequent rest. Participants were allowed to rest if required during any of the $30 \mathrm{~m}$ climbs and at any point, the number of rests and duration of these rests were dictated by the participant and recorded in terms of frequency and duration. This was based on a critical task analysis, which stated technicians climbed in pairs or three's and would be resting whilst the other/s climbed (Milligan et al, 2019). Each ladder climb was started with the participant standing stationary on the ladder, one of the project team would gradually increase the speed and stopped when the participants nodded that they had reached there self-selected pace. Participants used their preferred climbing technique. Neither the speed nor technique were standardised for the following reasons: 1 . These could not be established during the critical task analysis (Milligan et al, 2019) 2. Ensure EC and NC were not constrained, thus looking at their efficiency 3. Observe the variation in technique between EC and NC. 
On completion of each $30 \mathrm{~m}$ climb, participants were seated and whole body Rate of Perceived Exertion (6-20 RPE [Borg, 1982]) recorded. A rest period equal to the time it had taken to climb the previous $30 \mathrm{~m}$ was provided, thus slower climbers got a longer rest maintaining the 1:1 ratio. Participants repeated this three times to complete a total of $120 \mathrm{~m}$. On completion of the $120 \mathrm{~m}$, grip strength and RPE were recorded. Following 3 minutes of seated rest grip strength and $30 \mathrm{~s}$ endurance were measured and BLa were recorded. During the simulated ladder climb $20 \mathrm{~s} \dot{V} \mathrm{O}_{2}$ (Metamax 3B, Cortex, Italy), and $20 \mathrm{~s} \mathrm{HR}$ (Polar team system), EMG and kinematic data were measured continuously. This sequence was completed three times; each $120 \mathrm{~m}$ climb was separated by a minimum of 1 hour 15 minutes of rest.

\subsection{Measurements}

\subsubsection{Environmental Conditions}

The mean (SD) laboratory conditions were monitored for the duration of study: temperature $20.40(1.30){ }^{\circ} \mathrm{C}$; Barometric pressure - 766.52 (3.46) mmHg; and Humidity - 51.75 (9.98) \%.

\subsubsection{Grip Strength and Endurance}

Maximum grip strength tests were undertaken three times for each hand. The hand did not tilt, rest on the leg or table, and grip was a maximal squeeze not a snatch with the elbow held at 90 ${ }^{\circ}$, allowing $30 \mathrm{~s}$ rest between tests of the same hand (Douris et al, 2003). The endurance tests were completed once per hand, recorded as an average over the final $18 \mathrm{~s}$. The dynamometer was zeroed before each test.

\subsubsection{Oxygen Consumption and Heart Rate}


The metabolic response was measured using a Metamax 3B (Cortex, Italy). HR data were record using the Polar Team Pro system. Both were recorded for the duration of the exercise. Breath by breath and beat by beat data were recorded and converted to $20 \mathrm{~s}$ collections.

\subsubsection{Electromyography (EMG)}

The EMG equipment included the data logger (Biometrics Data Log P3X8, Biometrics Ltd, UK) and passive surface electrodes (Biometrics Pre- Amplifiers, Biometrics Ltd, UK). To measure muscle activity, surface EMG (mV) was employed, sampling at $1000 \mathrm{~Hz}$. Following preparation which involved cleaning the skin with an alcoholic wipe, and dry shaving the area, the participants had surface electrodes placed on the selected muscles; gastrocnemius $(\mathrm{G})$, flexor digitorum superficialis (FD), biceps brachii (BB) and anterior deltoid (AD). SENIAM guidelines were followed (http://www.seniam.org/) for specific electrode placement on each muscle. A reference electrode was placed on the clavicle of each participant.

\subsubsection{Kinematic data}

A Qualisys Optoelectronic system (OQUS 300, Sweden) captured each participant climbing using 10 cameras, sampling at $250 \mathrm{~Hz}$. Cameras were set at differing heights in a circle around the calibrated volume ( $4 \mathrm{~m} \mathrm{x} 4.5 \mathrm{~m} \mathrm{x} 3 \mathrm{~m})$. A total of 48 (20 joint markers, 28 cluster markers) passive retro reflective markers $(12 \mathrm{~mm})$ were placed on anatomical landmarks and tracked using the Qualisys Track Manager system (Qualisys, Sweden). The joint markers were placed on the anterior head, posterior head, acromion, lateral epicondyle of the humerus, ulnar styloid, PSIS, greater trochanter, lateral condyle of the femur, lateral malleolus, and $1^{\text {st }}$ metatarsal on both the left and right hand sides. Markers were also placed on the ladder to allow distances between the limbs of the participant and the ladder to be calculated at all times throughout the trial. A static trial of each participant was captured before beginning the movement. 


\subsection{Data Analysis}

\subsubsection{Metabolic and Cardiovascular Data}

To provide an insight into the physical demand of ascending a $120 \mathrm{~m}$ vertical ladder, peak (20

s) $\dot{V} \mathrm{O}_{2}$ and $\mathrm{HR}$ values were reported as individuals did not reach a steady state work rate. The respiratory exchange ratio (RER) was used to estimate the proportion of time spent metabolising energy aerobically $(\mathrm{RER} \leq 1)$ and anaerobically $(\mathrm{RER}>1)$ and HR data were categorised into zones.

\subsubsection{Kinematic Data}

Following data collection and identification of the markers in Qualisys (Qualisys, Sweden), data were exported as a C3D file to Visual 3D analysis software (C-Motion, USA) for analysis. Once the model had been reconstructed, it was applied to the movement trials. All markers were filtered using an optimised Butterworth filter within the Visual3D software prior to further analysis. Kinematic data was assessed between each of the three climbs and also between the beginning and end of the trial. Three kinematic variables are presented: 1) Toe clearance defined as the clearance between the toe marker and the rungs of the ladder; 2) Mean hip range of motion (ROM) used to display the application of the stronger lower limb muscles around the hip joint in climbing; 3) Peak shoulder flexion used to reflect the reach of the arms during climbing.

\subsubsection{Kinetic Data}

The EMG data were post processed using DataLink management and analysis software (Biometrics Ltd. UK). A differential technique was performed to reduce cross-talk of the EMG 
signal. The Raw EMG signal was processed in the time domain by computing the root mean square (RMS) value of the rectified signal. The peak RMS was calculated during the entire trial for each participant. All values exhibited by each participant in the trials were expressed as a percentage of each participant's peak value exhibited during the trial. This was achieved using the peak dynamic method. Any differences in activity in the muscles between the trials were reported as a percentage difference for each participant (NB: The values are a representation throughout the climbing period and are not individualised to each hand or foot movement).

\subsubsection{Statistical Analysis}

Data were statistically analysed using IBM SPSS 24.0 for Windows (SPSS Inc, Chicago, IL). Tests of normality were conducted to assess if the data were parametric using Shapiro-Wilk, Skewness and Kurtosis. If the data were found to be parametric, mixed model ANOVAs were used to determine significant differences (Factor $1=\operatorname{climb} 1,2$, or 3; Factor $2=$ Experience, EC vs NC) and interactions (Climb and Experience) on the dependant variables. If Sphericity could not be assumed, data were reported using the highest Epsilon value. Post-hoc analysis consisted of paired and independent samples $t$-tests with Bonferroni corrections applied. Effect sizes were calculated using Cohen's d (Cohen, 1988).

\subsection{Results}

\subsection{Fitness}

Table 2 details the fitness (aerobic and strength) data of the EC, NC and combined. There were no significant differences in predicted aerobic capacity $\left(\mathrm{t}_{(15)}=-0.132 ; \mathrm{p}=0.897\right)$; grip strength non-dominant hand $(\mathrm{ND})$ hand $\left(\mathrm{t}_{(15)}=1.032 ; \mathrm{p}=0.318\right)$ and the dominant hand $(\mathrm{D})\left(\mathrm{t}_{(15)}=\right.$ $1.252 ; \mathrm{p}=0.230)$ and grip endurance $\mathrm{ND}\left(\mathrm{t}_{(15)}=-0.4 .36 ; \mathrm{p}=0.669\right)$ grip endurance $\mathrm{D}\left(\mathrm{t}_{(15)}=\right.$ $-0.303 ; \mathrm{p}=0.766$ ) between the EC and the NC respectively. 
INSERT TABLE 2 HERE

\subsection{Climbing Speed and Times}

\subsubsection{Climbing Speed}

Self-selected climbing speed ranged between $9 \mathrm{~m} \cdot \mathrm{min}^{-1}$ (30 rungs.min $\left.{ }^{-1}\right)$ and $19.5 \mathrm{~m} \cdot \mathrm{min}^{-1}$ (65 rungs. $\mathrm{min}^{-1}$ ) for NC. EC selected climbing speeds between $13.5 \mathrm{~m} \cdot \mathrm{min}^{-1}\left(45\right.$ rungs. $\left.\mathrm{min}^{-1}\right)$ to 20 m. $\min ^{-1}\left(66.67\right.$ rungs. $\left.\mathrm{min}^{-1}\right)$. Twelve $(\mathrm{EC}=5 ; \mathrm{NC}=7)$ chose to increase speed over the $12 \mathrm{x}$ $30 \mathrm{~m}$ climbs. Two $\mathrm{NC}$ and one $\mathrm{EC}$ decided to reduce the speed and two $(\mathrm{EC}=1 ; \mathrm{NC}=1) \mathrm{kept}$ at the same speed for all the climbs (Table 3).

\section{INSERT TABLE 3 HERE}

End climbing speed, irrespective of climbing experience, was significantly different $\left(\mathrm{F}_{(1.514,22.703)}=7.816 ; \mathrm{p}=0.002\right)$ across the three climbs. With Climb $1\left(14.4[2.9] \mathrm{m} \cdot \mathrm{min}^{-1}[48\right.$ rungs. $\left.\left.\mathrm{min}^{-1}\right]\right)$ reporting a significantly $\left(t_{(16)}=-2.890 ; \mathrm{p}=0.011 ; d=-0.38\right)$ slower climbing speed than both Climb 2 (15.5 [2.9] m. $\mathrm{min}^{-1}\left[51.67\right.$ rungs.min $\left.\left.{ }^{-1}\right]\right)$ and Climb 3 (16.2 [3.3] m. $\min ^{-1}\left[54\right.$ rungs. $\left.\left.\mathrm{min}^{-1}\right] ; t_{(16)}=-3.249 ; \mathrm{p}=0.005 ; d=-0.58\right)$, there was no significant difference between Climbs 2 and 3.

\subsubsection{Total Time (climbing + rest time)}

In order to complete a $120 \mathrm{~m}$, climbers were climbing approximately a third of the total time. Total climbing time irrespective of climbing experience was significantly different $\left(\mathrm{F}_{(2,30)}=\right.$ 4.453; $\mathrm{p}=0.020)$. With Climb 1 being significantly faster than both Climb $2\left(t_{(16)}=-2.643 ; \mathrm{p}\right.$ 
$=0.018 ; d=-0.099)$ and Climb $3\left(t_{(16)}=-2.723 ; \mathrm{p}=0.015 ; d=-0.14\right)($ Tables 2$)$. There was no significant difference between Climbs 2 and 3.

Based on the mean data, EC climbed each $120 \mathrm{~m}, 3 \min 13 \mathrm{~s}($ Climb $1 ; d=1.04 ;), 4 \min 25 \mathrm{~s}$ (Climb $2 ; d=1.02)$, and $5 \min 14 \mathrm{~s}(\operatorname{Climb} 3 ; d=1.05)$ faster than the NC. With the EC climbing time remaining relatively consistent, whilst the novices became slower on each climb (Table 4).

INSERT TABLE 4 HERE

\subsection{Metabolic and Cardiorespiratory}

There were no significant differences $(p>0.05)$ in peak oxygen consumption across each 120

m climb (i.e. Climb 1, 2 and 3) or between climbers (i.e. EC vs NC, Table 2). There were no significant differences $(\mathrm{p}>0.05)$ between peak HR across each of the $120 \mathrm{~m}$ climbs. EC demonstrated significantly $\left(\mathrm{F}_{(1,15)}=2829.013 ; \mathrm{p} \leq 0.0001 ; d=\right)$ higher peak HRs than NC $(178$ [11.97] vs. 170 [13.64]) irrespective of the climb being undertaken (Table 5). On average across the three climbs EC achieved a peak HR of $97 \%$ of their age predicted HRmax, compared to $89 \%$ in the $\mathrm{NC}$.

\subsubsection{Aerobic and Anaerobic Contribution to Work}

Figure 2 demonstrates that during Climb 1 (climbing + rest) climbers spent significantly $\left(t_{(14)}\right.$ $=-8.8500 ; \mathrm{p}<0.001 ; d=-4.55)$ less time metabolising energy aerobically $(25[11] \%)$ than anaerobically $(75[11] \%)$. During climb 2 , climbers spent significantly $\left(t_{(14)}=-3.701 ; \mathrm{p}=\right.$ $0.002 ; d=-1.92)$ less time metabolising energy aerobically (38 [12] \%) than anaerobically (61 $[12] \%)$. During climb 3 there was no significant difference $\left(t_{(14)}=-0.358 ; \mathrm{p}=0.726 ; d=-0.17\right)$ in the time spent metabolising energy aerobically (48 [18] \%) and anaerobically (51 [18] \%). 
There were no significant differences between EC and NC; EC tended to work more anaerobically ( $3 \%, 8 \%$ and $6 \%$ for each climb respectively).

INSERT FIGURE 2 HERE

\subsubsection{Blood Lactate}

Post climb blood lactate values ranged from low $\left(2.4 \mathrm{mmol} . \mathrm{L}^{-1}\right)$ to high $\left(11.9 \mathrm{mmol} . \mathrm{L}^{-1}\right)$. The highest and lowest blood lactate values reported across each of the three climbs were by EC; these two climbers were the only two not to take a self-selected rest during any of the climbs.

Delta changes in blood lactate, irrespective of climbing experience, was significantly different across climbs $\left(\mathrm{F}_{(2,30)}=6.453 ; \mathrm{p}=0.002\right)$. With Climb 1 reporting significantly higher delta change than both Climb $2\left(t_{(15)}=3.312 ; \mathrm{p}=0.005 ; d=-0.69\right)$ and Climb $3\left(t_{(15)}=2.944 ; \mathrm{p}=\right.$ $0.010 ; d=-0.67$ ) (Table 5). There was no significant difference in blood lactate values between Climbs 2 and 3. Based on the mean blood lactate data, EC demonstrated a delta change of 2 mmol.L ${ }^{-1}($ Climb 1; $d=0.84 ;), 2$ mmol.L ${ }^{-1}($ Climb 2; $d=0.72)$, and 1.7 mmol.L ${ }^{-1}($ Climb 3; $d$ $=0.54)$ higher than the $\mathrm{NC}$ (Table 5). Blood lactates returned to resting levels before the start of each climb.

INSERT TABLE 5 HERE

\subsection{Grip Strength and Endurance}

Both the ND and D hands reported lower grip strength and endurance scores following each $120 \mathrm{~m}$ climb (Table 6). Grip strength and endurance remained significantly lowered at the start 
of the second and third $120 \mathrm{~m}$ climbs compared to the first (Table 6). There were no significant differences between grip strength and endurance at the start of the second compared to the third $120 \mathrm{~m}$ ladder climb. No Significant differences were reported between EC and NC for both grip strength and endurance.

On completion of the third ladder climb grip strength score had fallen by $46 \%$ in the ND hand and $43 \%$ in the D hand. Grip endurance fell by $40 \%$ in the ND hand and $41 \%$ in the D hand following the three climbs.

INSERT TABLE 6 HERE

\subsection{Kinetic and Kinematic}

\subsubsection{Kinematic}

A significant difference was found in the toe clearance $\left(\mathrm{F}_{(2,30)}=6.278 ; \mathrm{p}=0.002\right)$ over the three climbs, irrespective of experience. Toe clearance during Climb 2 was significantly $\left(\mathrm{t}_{(16)}=-\right.$ 2.711, $\mathrm{p}<0.01, d=1.08)$ less than Climb 1 . Toe clearance during Climb 3 was significantly $\left(\mathrm{t}_{(16)}=-3.160, \mathrm{p}<0.01, d=1.51\right)$ less than Climb 1. No significant difference was found between Climbs 2 and 3 (Table 4). A significant difference was found between the two groups $\left(\mathrm{F}_{(2,30)}=\right.$ $6.453 ; p=0.002$ ) with the EC having a significantly greater toe clearance than NC. Further analysis showed that EC had significantly $\left(\mathrm{t}_{(16)}=-1.990, \mathrm{p}=0.023, d=1.17\right)$ greater toe clearance during Climb 1 than the NC. No significant differences were found between EC and novice climber for climbs 2 and 3 (Table 7).

EC used a significantly $\left(\mathrm{F}_{(2,30)}=-3.572 \mathrm{p}=0.005\right)$ greater range of motion at the hip, than the NC. This difference between the two groups was evident in all three climbs Climb $1\left(t_{(16)}=-\right.$ 2.211, $\mathrm{p}=0.011, d=-1.63), \operatorname{Climb} 2\left(\mathrm{t}_{(16)}=-3.538, \mathrm{p}=0.001, d=-2.42\right)$ and $\operatorname{Climb} 3\left(\mathrm{t}_{(16)}=-\right.$ 3.677, $\mathrm{p}<0.001, d=-4.08)$. EC did not change their hip ROM between the climbs and were 
able to maintain the use of these large muscles of the lower limbs. NC reduced the hip ROM from Climb 1 to Climb 2 and again to Climb 3 (Table 7).

Peak shoulder flexion was found to be significantly $\left(\mathrm{F}_{(2,30)}=3.726 ; \mathrm{p}=0.001\right)$ different, irrespective of experience, between the three climbs. Significantly $\left(\mathrm{t}_{(16)}=-6.643 ; \mathrm{p}<0.001, d=\right.$ -1.47) greater shoulder flexion was found in Climb 2 compared to Climb 1 and in Climb 3 compared to Climb $1\left(\mathrm{t}_{(16)}=-7.643 ; \mathrm{p}<0.001 ; d=-1.89\right)$. No significant difference was found between Climb 2 and Climb 3. EC demonstrated significantly $\left(\mathrm{t}_{(16)}=4.09 ; \mathrm{p}=0.001, d=1.01\right)$ less shoulder flexion during Climb 1 than NC. There were no differences between EC and NC in climbs 2 and 3 (Table 7).

\subsubsection{Kinetic}

A significant $\left(\mathrm{F}_{(2,30)}=-3.028, \mathrm{p}=0.02\right)$ difference in forearm muscle activation, irrespective of experience, was found between climbs. Higher levels of forearm muscle activation were found for Climb 2 compared to Climb $1\left(\mathrm{t}_{(16)}=-3.011, \mathrm{p}=0.011, d=-1.4\right)$ and again between in Climb 3 compared to Climb $1\left(\mathrm{t}_{(16)}=-3.844, \mathrm{p}<0.001, d=-2.75\right)$. No differences were found between climbs 2 and 3. NC demonstrated significantly $\left(\mathrm{t}_{(16)}=-2.016, \mathrm{p}=0.004, d=-2.74\right)$ higher forearm muscle activation in Climb 2 and Climb $3\left(\mathrm{t}_{(16)}=-2.011, \mathrm{p}=0.023, d=-1.32\right)$ compared to the EC. No significant differences were found for Climb 1 (Table 7).

A significant $\left(\mathrm{F}_{(2,30)}=-2.678, \mathrm{p}=0.045\right)$ difference, irrespective of experience, was found between climbs for bicep muscle activation. Higher levels of bicep muscle activation were found for Climb 3 compared to Climb $1\left(\mathrm{t}_{(16)}=-3.611, \mathrm{p}<0.001, d=-2.21\right)$ and again between Climb 2 and Climb $3\left(\mathrm{t}_{(16)}=-3.277, \mathrm{p}<0.001, d=-2.15\right)$. No significant difference was found between Climb 1 and Climb 2. NC showed significantly $\left(\mathrm{t}_{(16)}=-2.016, \mathrm{p}=0.013, d=-1.22\right.$ ) 
higher muscle activation in the bicep during Climb 3. No significant differences between the groups were found for climbs 1 and 2 (Table 7).

A significant $\left(\mathrm{F}_{(2,30)}=-3.702, \mathrm{p}<0.001\right)$ difference, irrespective of experience, was found between climbs for muscle activation in the anterior deltoid. Higher levels of anterior deltoid muscle activation were found for Climb 2 compared to Climb $1\left(\mathrm{t}_{(16)}=-1.911, \mathrm{p}=0.021, d=\right.$ 2.766) and again between in Climb 3 compared to Climb $1(\mathrm{p}<0.001) .\left(\mathrm{t}_{(16)}=3.011, \mathrm{p}<0.001\right.$, $d=-1.4)$. NC demonstrated a significantly greater anterior deltoid muscle activation than the EC during Climb $1\left(\mathrm{t}_{(16)}=1.811, \mathrm{p}=0.031, d=-1.40\right), \operatorname{Climb} 2\left(\mathrm{t}_{(16)}=-2.461, \mathrm{p}=0.042, d=\right.$ 3.90) and Climb $3\left(\mathrm{t}_{(16)}=2.411, \mathrm{p}=0.038, d=2.13\right)($ Table 7$)$.

No significant differences were found for the calf muscle group activation across each of the climbs. Visual inspection of these data suggesting increases for both groups across each of the climbs, however, there were large SD for both groups in all climbs.

INSERT TABLE 7 HERE

\subsection{Discussion}

The primary aim of this study was to determine ergonomics of prolonged ladder climbing, over the working day. Ascending a $120 \mathrm{~m}$ vertical ladder was shown to require a high physical demand, as demonstrated by the percentage of time spent metabolising energy anaerobically, when $2 / 3$ of the total time taken to complete the climb was spent resting. This is also supported by high peak HRs $\left(\sim 173\right.$ b. $\mathrm{min}^{-1}$ across the three climbs $)$ and $\dot{V} \mathrm{O}_{2}\left(\sim 3.1 \mathrm{~L}^{\mathrm{min}} \mathrm{m}^{-1}\right.$ across the three climbs). These data are substantially higher than the physical demands reported in other studies (Kamon, 1970; Vi, 2008; Milligan, 2013; Barron et al, 2018). A number of factors could have influenced these differences and direct comparisons between these studies is limited: 
1. Some of the studies were performed ascending and descending short fixed ladders (Kamon, 1970; Vi, 2008; Milligan, 2013).

2. The climbing rates in these studies were on for the most part slower (17 rung. $\min ^{-1}$ to 34.5 rungs. $\mathrm{min}^{-1}$ ) compared to those in the current study ( 30 rungs. $\mathrm{min}^{-1}$ to 66.67 rungs. $\left.\min ^{-1}\right)$.

3. The data reported in the current study are reported as a $20 \mathrm{~s}$ peak $\dot{V} \mathrm{O}_{2}$ or $\mathrm{HR}$. The reason for this being two-fold: i) participants were able to take breaks adlib and thus did not reach a steady state work rate or ii) individuals completed the climb in one go, in a time to fast to elicited a steady state response.

Participants in the current study self-selected their ascending speed and where able to take rest breaks adlib, unlike other studies, where the climbing speed was fixed and climbing stopped if participants were unable to complete the required climb (Milligan, 2013; Barron, 2018). The rationale for adopting this methodology, as opposed to controlling the climbing speed, was threefold: 1 . Speeds and rest times could not be established during the critical task analysis (Milligan et al, 2019) 2. To ensure EC and NC were not constrained, thus looking at their efficiency 3. Observe the variation in technique between EC and NC. EC and NC chose to climb between 30 rungs. $\mathrm{min}^{-1}$ to 66.67 rungs. $\mathrm{min}^{-1}$, with individuals reporting that the slower they climbed the more fatigue they felt in their arms. This suggest that minimum climbing speeds recommend for the Oil and Gas Industry (24 rungs. $\mathrm{min}^{-1}$ and 34.5 rungs.min ${ }^{-1}$ ) may not suitable for use within Wind Power, and should not be used to set standards to assess physical fitness. Further work is required to determine an acceptable climbing speed that minimises forearm fatigue.

The primary aim of this study was to understand the ergonomics placed on technicians during prolonged ladder climbing over the working day. Significant fatigue was demonstrated in all climbers between climbs 1 and 2 and 1 and 3 as demonstrated by slower total climbing speeds 
from climb 1 to climbs 2 and 3. Reductions in grip strength and endurance of pre and post each climb were approximately $35 \%$ and $26 \%$ respectively. These data are greater than those reported by previous research (Leyk et al, 2006; Milligan, 2013, Stewart \& Mitchell, 2018), with decrements in maximum grip strength of $20 \%$, resulting in poorer performance of fine motor skills (Leyk et al, 2006). Thus, the impact this level of fatigue could have on technicians being able to perform tasks directly proceeding a ladder climb of $120 \mathrm{~m}$ should be considered.

Changes were observed in the shoulder joint which suggested that as fatigue increased, due to multiple climbs, participants were changing their technique to reach higher with their arms. The increased shoulder flexion angles of both groups after the first climb (Climb $1-117^{\circ}$ climb $2-133^{\circ}$; climb $3-136^{\circ}$; see Table 7) demonstrates that one climb is sufficient to increase the amount of reaching for the rungs of the ladder. It has been shown (non-ladder climbing specific) that this repetitive movement in shoulder movement leads to an increased risk of chronic shoulder injuries (Sood et al, 2007; Linaker \& Walker-Bone, 2015).

Increased levels of fatigue associated with multiple climbs, saw a reduction in toe clearance between the toe and the ladder. Limited foot movement away from the ladder during climbing has been shown to increase the likelihood of trips and potential for injury (Pliner et al, 2014). The significant decreases presented in this study between climb 1 and climbs 2 and 3 indicates that the climbers are increasing the risk of trips. Additionally the distance decreases after the first climb for both groups showing a single $120 \mathrm{~m}$ climb can make an EC more susceptible to tripping. The SD for both the $\mathrm{NC}$ and EC increased as the climbs continue; this indicates that the participants became more variable in foot movement patterns as the climbs continued. Minimum toe clearance space in front of and behind the ladder has been examined by the US Mining Safety and Health Administration (MSHA) and requires that ladders be placed at least $76 \mathrm{~mm}$ away from other surfaces. In contrast the US Occupational Safety and Health Administration (OSHA) requires a $180 \mathrm{~mm}$ clearance. These conflicting toe clearance 
regulations suggest that an understanding of the effects of restricted toe clearance on slip risk is needed to assess the appropriateness of the different guidelines and to set a minimum acceptable requirement for toe clearance for prolonged ladder climbing. The present study expand on these recommendations by highlighting the role of fatigue on reducing this distances, regardless of any obstacle present.

The secondary aim of this study was to compare NC to EC, it was found that EC demonstrated faster climbing speeds, took less rest, had fewer self-selected rest breaks and ultimately took less time (Climb $1=3 \min 13 \mathrm{~s}$; Climb $2=4 \min 25 \mathrm{~s}$ and Climb $3=5 \min 14 \mathrm{~s}$ ) to complete each of the three $120 \mathrm{~m}$ climbs, than the $\mathrm{NC}$, without reporting significantly greater aerobic and anaerobic requirements. The tendency for EC to work more anaerobically is like due to completing the climbs at a faster rate and in less time. It should be noted that a larger variation was observed within the $\mathrm{NC}$, with some performing to the same levels as the EC. The data presented suggest that whilst the EC were neither fitter nor stronger than the NC, their experience meant they were better suited to dealing with the physical demand of the climbs.

A unique aspect of this research was the use of kinematic data to compare NC to EC. Novice climbers demonstrated less range of movement through the hips and a higher proportion of muscle activation in the upper body than the EC. This means they were using less of the large muscle groups of the legs and more of the small muscles in the arms. The use of smaller muscles in the arm led to fatigue as early as the second climb. Almost all participants, irrespective of climbing experience, reported that the forearms were a limiting factor in the climbing performance. The EC did not increase the use of the forearm from the first to the second climb. However, this increased significantly in the final climb. The novices increased from the first to the second and again to the final climb. This would indicate that the familiarity with climbing limited the use of this smaller muscle until the final climb. Anecdotally, it was observed that some $\mathrm{NC}$ changed their technique dramatically in the final climb, allowing them 
to continue climbing when grip strength had reduced. This may have led to large standard deviations in the data with the forearm registering higher values if the same technique had continued. From a practical perspective, the significant increase from Climb 1 to Climb 2 suggests consideration should be taken when climbing $120 \mathrm{~m}$ more than once in a day, ultimately, leading to greater fatigue and increase the likelihood of injuries through both chronic overuse injuries or acute injuries resulting from loss of grip. Although all climbers have a fall arrest harness to prevent a large fall, injuries may occur due to strained muscles in a bid to reattach to the ladder or banging of limbs onto the ladder.

A limitation of this study was the inclusion of additional PPE (2.3 $\mathrm{kg}$ sea survival suit and lifejacket) for EC during the first climb. The work presented in this study was part of a larger project for which there was a need to include the additional PPE. The authors acknowledge comparisons made to the first climb for EC may skew the data. The rationale for including these data in the comparisons and the impact on the data the additional PPE may have had are as follows: Climbing times were faster in $\mathrm{EC}$ than $\mathrm{NC}$ even with the addition of $2.3 \mathrm{~kg}$. The median number of rest breaks did not change for EC across all climbs. The physiological and kinematic data suggests minimal differences between climb 1 and 2, with climb 3 being greater than climb 1. These data still highlight the difference between EC and NC, the main impacts of including the $2.3 \mathrm{~kg}$ are; the difference between the $\mathrm{EC}$ and $\mathrm{NC}$ in during the first climb; and the magnitude of fatigue encountered during climbs 1 and 2 for EC, could be underestimated.

\subsection{Conclusion}

It is concluded that ladder climbing technique and experience improves performance, reduces the physiological burden and maintains optimal movement patterns for longer. Therefore, it is recommended that future work evaluates: what constitutes an EC; the role body size plays in 
climbing ability and efficiency; if their tis an optimal climbing speed to reduce forearm fatigue, optimise climbing ability and minimise the risk of injury; what the minimum acceptable standards are to climb a ladder in the Wind Power Industry; how long it takes to become proficient at prolonged ladder climbing using the minimum acceptable standards; and if training can improve the time to proficiency.

\subsection{Acknowledgements}

We would like to thank: the Energy Institute and $\mathrm{G}^{+}$; the subject matter experts from SSE and eon; Dan McKinley, Marcus Peters and Kate Harvey. 


\subsection{References}

Armstrong T.J., Young J., Woolley C., Ashton-Miller J. and Kim H. (2009). "Biomechanical Aspects of Fixed Ladder Climbing: Style, Ladder Tilt and Carrying." Proceedings of the Human Factors and Ergonomics Society 53rd Annual Meeting, San Antonio. 935-939 https://doi.org/10.1177/154193120905301417

Barron, P.J., Burgess, K., Cooper, K., and Stewart, A.D. (2017). The physiological effect of a'climb assist'device on vertical ladder climbing. Ergonomics, 60 (7), 1008-1013 https://doi.org/10.1080/00140139.2016.1244290

Barron, P.J., Burgess, K., Cooper, K., and Stewart, A.D. (2018). The effect of pitched and vertical ladder ergometer climbing on cardiorespiratory and psychophysical variables. Applied Ergonomics. (66), 172-176 https://doi.org/10.1016/j.apergo.2017.09.001

Barnett, R., and Poczynck, P. 2000. “Ladder Rung vs. Siderail Hand Grip Strategies.”Safety Brief (Triodyne Inc.).16 (4), 1-15

Bloswick D.S., and Chaffin, D.B. (1990) An ergonomic analysis of the ladder climbing activity. International Journal of Industrial Ergonomics. 6, 17-27 https://doi.org/10.1016/0169$\underline{8141(90) 90047-6}$

Borg, G. A. (1982). Psychophysical bases of perceived exertion. Medicine and Science in Sports and Exercise, 14(5), 377-381. https://doi.org/10.1249/00005768-198205000-00012

Cohen, J. (1988). Statistical power analysis for the behavioural sciences, 2nd Ed. Hillside New Jersey: Lawrence Erlbaum Associates 
Douris, P., McKenna, R., Madigan, K., Cesarski, B., Costiera, R., and Lu, M. (2003). Recovery of maximal isometric grip strength following cold immersion. Journal of Strength and Conditioning Research. 17(3), 509-513 https://doi.org/10.1519/00124278-200308000-00014

Cohen, J. (1988). Statistical power analysis for the behavioural sciences, 2nd Ed. Hillside New Jersey: Lawrence Erlbaum Associates

Gledhill, N., and Jamnik, V.K. (1992). Characterization of the physical demands of firefighting. Canadian Journal of Sport Sciences 17(3), 207-213

Hammer W, Schmalz U. (1992). Human behaviour when climbing ladders with varying inclinations. Safety Science. 1;15(1), 21-38. https://doi.org/10.1016/0925-7535(92)90037-Z

Henderson, A.R., Morgan, C., Smith, B., Sørensen, H.C., Barthelmie, R.J., Boesmans B. (2003). Offshore wind energy in Europe - a review of the state-of-the-art. Wind Energy: An International Journal for Progress and Applications in Wind Power Conversion Technology. 6(1), 35-52 https://doi.org/10.1002/we.82

Kamon, E. (1970) Negative and Positive work in Climbing a Laddermill. Journal of Applied Physiology. 29(1), 1-5 https://doi.org/10.1152/jappl.1970.29.1.1

Kamon, E., and Pandolf, K.B. (1972) Maximal Aerobic Power during Laddermill Climbing, Uphill Running and Cycling. Journal of Applied Physiology. 32(4), 467-473 https://doi.org/10.1152/jappl.1972.32.4.467 
Kamon, E., Metz, K.F., and Pandolf, K.B. (1973) Climbing and cycling with additional weights on the extremities Journal of Applied Physiology. 35(3), 367-370 https://doi.org/10.1152/jappl.1973.35.3.367

Leyk, D., Rode, U., Erley, O., Gorges, W., Wunderlich, M., Rther, T., and Essfeld, D. (2006). Recovery of hand grip strength and hand steadiness after exhausting manual stretcher carriage. European Journal of Applied Physiology. 96, 593-599 https://doi.org/10.1007/s00421-005$\underline{0126-0}$

Linaker, C.H., and Walker-Bone, K. (2015). Best Practice Research in Clinical Rheumatology. Shoulder Disorders and Occupation. 29(3), 405-423 https://doi.org/10.1016/j.berh.2015.04.001

McIntyre, D.R. (1983). Gait patterns during free choice ladder ascents. Human Movement Science. 2(3), 187-195 https://doi.org/10.1016/0167-9457(83)90016-7

Milligan, G.S. (2013). Fitness Standards for the Maritime and Coastguard Agency and the Oil and Gas Industry. PhD thesis. University of Portsmouth.

Milligan, G. S., O’Halloran, J. P., and Tipton, M. J. (2019). A job task analysis for Technicians in the Offshore Wind Industry. Work, (Preprint), 1-9. https://doi.org/10.3233/WOR-19296

Pliner, E.M., Campbell-Kyureghyan, N. H., and Beschorner, K.E. (2014). Effects of foot placement, hand positioning, age and climbing biodynamics on ladder slip outcomes. Ergonomics. 57(11), 1739-1749 https://doi.org/10.1080/00140139.2014.943681 
Pliner, E.M., Seo, N.J., and Beschorner, K.E. (2015). Hand and foot responses that improve ladder fall recovery. Paper presented at the American Society of Biomechanics, Columbus, $\mathrm{OH}$

Pliner, E. M., Seo, N. J., and Beschorner, K. E. (2017). Factors affecting fall severity from a ladder: Impact of climbing direction, gloves, gender and adaptation. Applied Ergonomics. 60, 163-170 https://doi.org/10.1016/j.apergo.2016.11.011

Pliner, E., and Beschorner, K.T. (2017). Effects of Ladder Climbing Patterns on Fall Severity Proceedings of the Human Factors and Ergonomics Society 2017 Annual Meeting Volume: 61 (1) 940-944 https://doi.org/10.1177/1541931213601717

Tipton, M. J., Milligan, G. S., and Reilly, T. J. (2013). Physiological employment standards I. Occupational fitness standards: objectively subjective?. European Journal of Applied Physiology, 113(10), 2435-2446. https://doi.org/10.1007/s00421-012-2569-4

Schnorenberg, A.J., Campbell-Kyureghyan, N.H., and Beschorner, K.E. (2015). Biomechanical response to ladder slipping events: Effects of hand placement. Journal of Biomechanics. 48(14), 3810-3815 https://doi.org/10.1016/j.jbiomech.2015.09.001

Sood D, Nussbaum M.A, Hager K. (2007) Fatigue during prolonged intermittent overhead work: reliability of measures and effects of working height. Ergonomics. 50(4), 497-513 https://doi.org/10.1080/00140130601133800

Stewart, A., Marfell-Jones, M., Olds, T., and Ridder, D. H. (2011). International Society for Advancement of Kinanthropometry. International standards for anthropometric assessment. 
Lower Hutt, New Zealand: International Society for the Advancement of Kinanthropometry, 125.

Stewart, A. D., and Mitchell, D. (2018). The effect of ladder climbing on forearm function. Contemporary Ergonomics and Human Factors 2018. Eds. Charles, R and Wilkinson J. Proceedings of the Chartered Institute of Ergonomics and Human Factors Conference 'Contemporary Ergonomics and Human Factors', Birmingham April 2018, edited by Rebecca Charles and John Wilkinson, pp 195-201.

Sykes, K., and Roberts, A. (2004). The Chester step test-a simple yet effective tool for the $\begin{array}{lllll}\text { prediction of } & \text { aerobic } & \text { capacity. Physiotherapy. } & 90(4), 188\end{array}$ https://doi.org/10.1016/j.physio.2004.03.008

Vi, P. (2008). Effects of Ladder Types on Energy Expenditure and Forearm Force Exertion during Ladder Climbing, 2008 National Occupational Injury Research Symposium (NOIRS). Pittsburgh, Pennsylvania. October $21-23$

Young, J.G., Woolley, C, Armstrong, T.J and Ashton-Miller, J.A. (2009). "Hand-Handhold Coupling: Effect of Handle Shape, Orientation, and Friction on Breakaway Strength." Human Factors: The Journal of the Human Factors and Ergonomics Society. 51(5): 705-717 https://doi.org/10.1177/0018720809355969 
Table 1. Demographic and anthropometric data $(\mathrm{n}=17 ; \mathrm{EC} \mathrm{n}=7 ;$ Male = 5, Female =2: $\mathrm{NC}$ n = 10; Male =9, Female = 1).

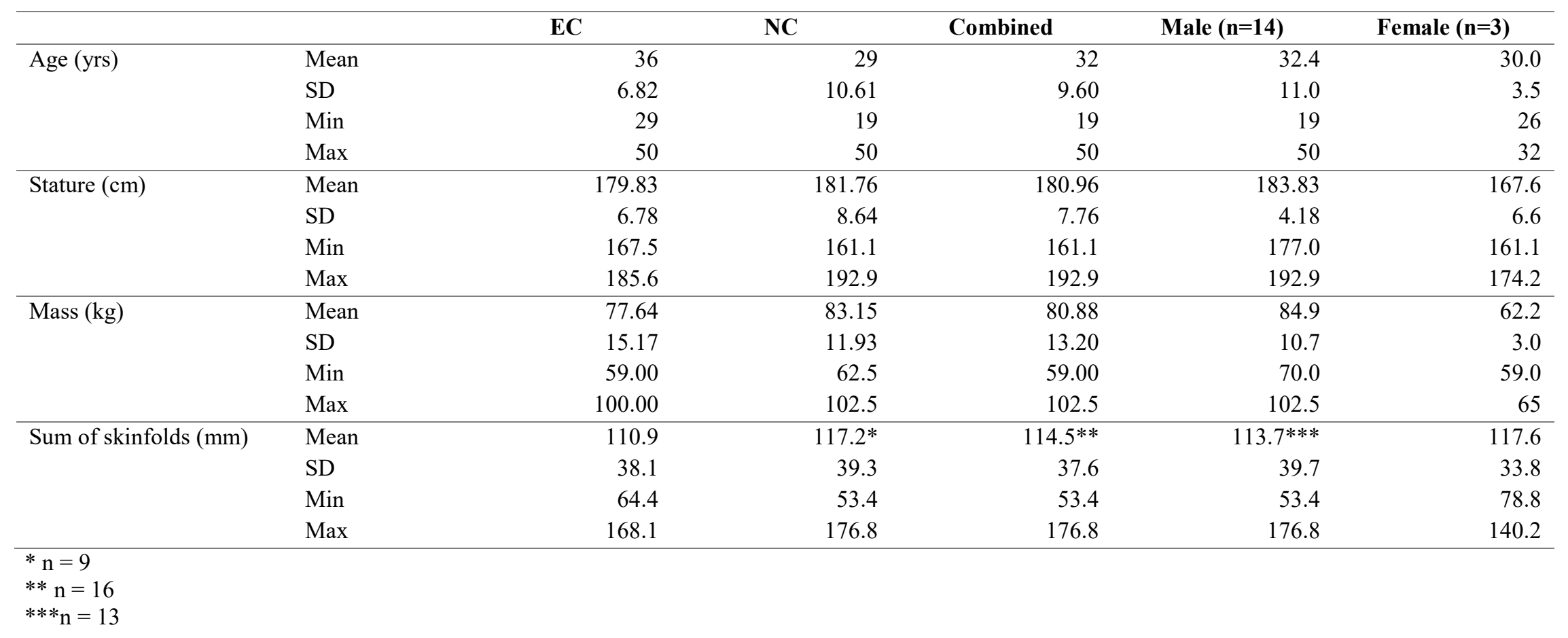


Table 2. Fitness data of Elite and Novice Climbers $(\mathrm{EC} \mathrm{n}=7$; Male $=5$, Female $=2: \mathrm{NC} n=10$; Male $=9$, Female $=1$ ).

\begin{tabular}{llrrrr}
\hline & & EC & \multicolumn{3}{c}{ NC } \\
\hline Aerobic capacity & Mean & & 52.86 & & 52.40 \\
$\dot{V} \mathrm{O}_{2 \max }\left(\mathrm{mL}^{-1} \mathrm{~kg}^{-1} \cdot \mathrm{min}^{-1}\right)$ & SD & & 7.62 & & 7.62 \\
& Min & & 48.00 & & 36.00 \\
& Max & & 61.00 & & 65.00 \\
\hline Max Grip Strength (kg) & & $\mathrm{ND} *$ & $\mathrm{D} * *$ & $\mathrm{ND}$ & $\mathrm{D}$ \\
& Mean & 39.09 & 40.54 & 42.85 & 45.34 \\
& SD & 6.69 & 8.73 & 7.84 & 7.07 \\
& Min & 29.30 & 28.30 & 35.50 & 36.10 \\
& Max & 46.60 & 53.50 & 59.60 & 61.70 \\
\hline Grip Endurance $(\mathrm{kg}) * * *$ & & $\mathrm{ND}$ & $\mathrm{D}$ & $\mathrm{ND}$ & $\mathrm{D}$ \\
& Mean & 26.07 & 25.24 & 24.97 & 24.47 \\
& SD & 5.02 & 4.20 & 5.19 & 5.74 \\
& Min & 17.00 & 18.50 & 19.10 & 13.40 \\
& Max & 30.90 & 30.60 & 33.00 & 31.20 \\
\hline
\end{tabular}

* ND $=$ Non-dominant hand $* * \mathrm{D}=$ Dominant hand 
Table 3. Elite and Novice mean (SD) climbing speeds $\left(\mathrm{m} \cdot \mathrm{min}^{-1}\right)$ for at each $30 \mathrm{~m}$ ascent.

\begin{tabular}{|c|c|c|c|c|c|c|c|c|c|c|c|c|}
\hline \multirow{2}{*}{$\begin{array}{c}\text { Climbing } \\
\text { Speed } \\
\text { m.min }\end{array}$} & \multicolumn{4}{|c|}{ Climb 1} & \multicolumn{4}{|c|}{ Climb 2} & \multicolumn{4}{|c|}{ Climb 3} \\
\hline & $30 \mathrm{~m}$ & $60 \mathrm{~m}$ & $90 \mathrm{~m}$ & $120 \mathrm{~m}$ & $30 \mathrm{~m}$ & $60 \mathrm{~m}$ & $90 \mathrm{~m}$ & $120 \mathrm{~m}$ & $30 \mathrm{~m}$ & $60 \mathrm{~m}$ & $90 \mathrm{~m}$ & $120 \mathrm{~m}$ \\
\hline \multicolumn{13}{|l|}{ NC } \\
\hline Mean & 12.5 & 12.9 & 13.6 & 14.2 & 14.5 & 14.5 & 14.7 & 14.9 & 15.2 & 15.4 & 15.4 & 15.5 \\
\hline SD & 3.1 & 3.3 & 3.5 & 3.9 & 3.5 & 3.6 & 3.5 & 3.6 & 3.8 & 4.0 & 4.0 & 3.9 \\
\hline Min & 9.0 & 9.0 & 9.0 & 9.0 & 9.0 & 9.0 & 9.0 & 9.0 & 9.0 & 9.0 & 9.0 & 9.0 \\
\hline Max & 17.0 & 17.0 & 19.0 & 19.0 & 19.0 & 19.0 & 19.0 & 19.0 & 19.0 & 19.5 & 19.5 & 19.5 \\
\hline \multicolumn{13}{|l|}{ EC } \\
\hline Mean & 16.0 & 15.9 & 15.9 & 15.9 & 16.5 & 16.9 & 16.9 & 16.9 & 17.3 & 17.3 & 17.3 & 17.3 \\
\hline SD & 1.4 & 0.9 & 0.9 & 0.9 & 0.6 & 1.1 & 1.2 & 1.2 & 2.0 & 2.0 & 2.0 & 2.0 \\
\hline Min & 13.5 & 14.5 & 14.5 & 14.5 & 15.5 & 15.5 & 15.5 & 15.5 & 15.0 & 15.0 & 15.0 & 15.0 \\
\hline Max & 17.5 & 17.0 & 17.0 & 17.0 & 17.0 & 18.5 & 19.0 & 19.0 & 20.0 & 20.0 & 20.0 & 20.0 \\
\hline
\end{tabular}


Table 4. Climbing and rest times for three ascents of $120 \mathrm{~m}(4 \times 30 \mathrm{~m}$ climbs $)(\mathrm{n}=17 ; \mathrm{EC} \mathrm{n}=7 ;$ Male $=5$, Female $=2: \mathrm{NC} \mathrm{n}=10 ;$ Male $=9$, Female $=1)$.

\begin{tabular}{|c|c|c|c|c|c|c|c|c|c|c|}
\hline & & \multicolumn{3}{|c|}{ CLIMB 1} & \multicolumn{3}{|c|}{ CLIMB 2} & \multicolumn{3}{|c|}{ CLIMB 3} \\
\hline & & $\mathrm{EC}^{*}$ & $\mathrm{NC}$ & Combined & $\mathrm{EC}$ & $\mathrm{NC}$ & Combined & $\mathrm{EC}$ & $\mathrm{NC}$ & Combined \\
\hline \multirow{4}{*}{$\begin{array}{l}\text { Time spent } \\
\text { climbing } 120 \mathrm{~m} \\
(4 \times 30 \mathrm{~m} \\
\text { climbs })(\text { min:s) }\end{array}$} & Mean & $8: 07$ & $10: 40$ & $9: 57$ & $8: 10$ & $10: 32$ & $9: 34$ & $7: 58$ & $10: 18$ & $9: 20$ \\
\hline & SD & $0: 33$ & $3: 08$ & $2: 21$ & $0: 26$ & $2: 44$ & $2: 23$ & $0: 23$ & $2: 37$ & $2: 18$ \\
\hline & Min & $7: 15$ & $7: 30$ & $7: 15$ & $7: 32$ & $7: 07$ & $7: 07$ & $7: 21$ & $7: 02$ & $7: 02$ \\
\hline & Max & $9: 45$ & $16: 16$ & $16: 16$ & $9: 34$ & $16: 49$ & $16: 49$ & $8: 22$ & $14: 23$ & $14: 23$ \\
\hline \multirow{4}{*}{$\begin{array}{l}\text { Time spent } \\
\text { resting during } 4 \\
\text { x } 30 \mathrm{~m} \text { climbs** } \\
\text { (min:s) }\end{array}$} & Mean & $3: 12$ & $4: 52$ & $4: 11$ & $3: 31$ & $5: 35$ & $4: 44$ & $3: 29$ & $6: 24$ & $5: 12$ \\
\hline & SD & $2: 43$ & $3: 33$ & $3: 15$ & $3: 12$ & $3: 51$ & $3: 38$ & $2: 53$ & $4: 20$ & $2: 18$ \\
\hline & Min & 0 & $0: 30$ & 0 & 0 & $0: 30$ & 0 & 0 & $0: 30$ & 0 \\
\hline & Max & $6: 41$ & $10: 35$ & $10: 35$ & $7: 23$ & $11: 32$ & $11: 32$ & $7: 50$ & $13: 22$ & $13: 22$ \\
\hline \multirow{4}{*}{$\begin{array}{l}\text { No. of rest } \\
\text { breaks taken } \\
\text { during } 4 \text { × } 30 \mathrm{~m} \\
\text { climbs }\end{array}$} & Median & 4 & 4 & 4 & 4 & 5 & 4 & 4 & 7 & 5 \\
\hline & Range & 5 & 11 & 12 & 5 & 12 & 13 & 5 & 13 & 14 \\
\hline & Min & 0 & 1 & 0 & 0 & 1 & 0 & 0 & 1 & 0 \\
\hline & Max & 5 & 12 & 12 & 5 & 13 & 13 & 5 & 14 & 14 \\
\hline \multirow{4}{*}{$\begin{array}{l}\text { Total climbing } \\
\text { time (min:s)*** }\end{array}$} & Mean & $11: 19$ & $15: 32$ & $13: 48$ & $11: 42$ & $16: 07$ & $14: 18$ & $11: 27$ & $16: 41$ & $14: 32$ \\
\hline & SD & $2: 50$ & $5: 20$ & $4: 51$ & $3: 24$ & $5: 50$ & $5: 20$ & $2: 58$ & $6: 08$ & $5: 37$ \\
\hline & Min & $7: 35$ & 8:00 & $7: 35$ & $7: 32$ & $10: 36$ & $7: 32$ & $7: 32$ & $7: 50$ & $7: 32$ \\
\hline & $\operatorname{Max}$ & $14: 33$ & $24: 43$ & $24: 43$ & $15: 45$ & $25: 02$ & $25: 02$ & $15: 56$ & $26: 00$ & $26: 00$ \\
\hline
\end{tabular}

* This climb was undertaken with the addition of a sea survival suit

** The number and the duration of the rest taken during the $30 \mathrm{~m}$ climb was self-selected

*** The rest time reported only includes rest taken during the climbs it does not take into account the rest provided after each $30 \mathrm{~m}$ climb which was set for each individual based on the time taken to climb the proceeding $30 \mathrm{~m}$. 
Table 5. Peak oxygen consumption $\left(\right.$ absolute $=\mathrm{L} \cdot \mathrm{min}^{-1}$; Relative $\left.=\mathrm{mL} \cdot \mathrm{kg}^{-1} \cdot \mathrm{min}^{-1}\right)$, percentage of predicted maximum oxygen uptake, peak heart rate $\left(\mathrm{b} \cdot \mathrm{min}^{-1}\right)$ and blood lactate $\left(\mathrm{mmol}^{-1}\right)$ for each $120 \mathrm{~m}(4 \times 30 \mathrm{~m}$ climbs $)$ ascent $(\mathrm{n}=17 \mathrm{EC} \mathrm{n}=7 ;$ Male $=5$, Female $=2: \mathrm{NC} \mathrm{n}=10 ;$ Male $=$ 9, Female =1).

\begin{tabular}{|c|c|c|c|c|c|c|c|c|c|c|}
\hline & & \multicolumn{3}{|c|}{ Climb 1} & \multicolumn{3}{|c|}{ Climb 2} & \multicolumn{3}{|c|}{ Climb 3} \\
\hline & & $\mathrm{EC}^{*}$ & $\mathrm{NC}$ & Combined & $\mathrm{EC}$ & $\mathrm{NC}$ & Combined & $\mathrm{EC}$ & $\mathrm{NC}$ & Combined \\
\hline \multirow{4}{*}{ L.min ${ }^{-1}$} & Mean & 3.05 & 3.11 & 3.08 & 3.02 & $\wedge 3.09$ & $\wedge 3.06$ & $\wedge \wedge 3.17$ & $\wedge \wedge 3.13$ & $\wedge \wedge 3.15$ \\
\hline & SD & 0.44 & 0.42 & 0.48 & 0.53 & 0.35 & 0.53 & 0.45 & 0.32 & 0.37 \\
\hline & Min & 2.27 & 2.24 & 2.24 & 2.00 & 2.43 & 2 & 2.44 & 2.47 & 2.44 \\
\hline & Max & 3.77 & 3.72 & 3.77 & 3.71 & 3.68 & 3.71 & 3.92 & 3.81 & 3.92 \\
\hline \multirow{4}{*}{$\mathrm{mL} \cdot \mathrm{kg}^{-1} \cdot \mathrm{min}^{-1}$} & Mean & 39.73 & 37.28 & 38.30 & 39.25 & $\wedge 38.05$ & $\wedge 38.57$ & $\wedge \wedge 42.32$ & $\wedge \wedge 37.77$ & ^^39.40 \\
\hline & SD & 5.16 & 3.69 & 4.50 & 5.28 & 5.68 & 5.50 & 5.96 & 4.80 & 5.64 \\
\hline & Min & 33.6 & 31.71 & 31.71 & 32.62 & 26.15 & 26.15 & 30.10 & 28.59 & 28.59 \\
\hline & Max & 52.73 & 47.29 & 52.73 & 51.47 & 51.14 & 51.47 & 54.83 & 46.71 & 54.83 \\
\hline \multirow[t]{4}{*}{$\% \dot{V} \mathrm{O}_{2 \max } *$} & Mean & 76 & 72 & 74 & 75 & 74 & 74 & 78 & 69 & 73 \\
\hline & Range & 8 & 14 & 12 & 9 & 13 & 11 & 12 & 9 & 11 \\
\hline & Min & 64 & 49 & 49 & 62 & 54 & 54 & 66 & 54 & 54 \\
\hline & Max & 94 & 109 & 109 & 92 & 104 & 104 & 98 & 87 & 98 \\
\hline \multirow{4}{*}{ b. $\min ^{-1}$} & Mean & 179 & 170 & 174 & 177 & 171 & 173 & 179 & 169 & 173 \\
\hline & $\mathrm{SD}$ & 11 & 14 & 13 & 13 & 14 & 14 & 14 & 14 & 14 \\
\hline & Min & 159 & 146 & 146 & 157 & 145 & 145 & 157 & 145 & 145 \\
\hline & Max & 187 & 192 & 192 & 192 & 191 & 192 & 194 & 192 & 192 \\
\hline \multirow[t]{4}{*}{$\mathrm{mmol} . \mathrm{L}^{-1}$} & Mean & 7.40 & $5.40^{\#}$ & $6.30 \# \#$ & 5.70 & 3.70 & 4.50 & 5.40 & 3.70 & 4.50 \\
\hline & $\mathrm{SD}$ & 3.00 & 1.50 & 2.40 & 3.10 & 2.40 & 2.80 & 3.20 & 3.10 & 2.80 \\
\hline & Min & 1.70 & 2.20 & 1.70 & 1.20 & 1.00 & 1.00 & 0.70 & 0.30 & 1.00 \\
\hline & Max & 10.50 & 7.00 & 10.50 & 10.10 & 8.00 & 10.10 & 10.80 & 7.00 & 10.10 \\
\hline
\end{tabular}

$* \% \dot{V} \mathrm{O}_{2 \max }$ is calculated based on the maximum oxygen uptake scores predicted from the Chester step test.

** This climb was undertaken with the addition of a sea survival suit

${ }^{\wedge} \mathrm{n}=16 ; \mathrm{NCs}=9$

${ }^{\wedge} \mathrm{n}=14 ; \mathrm{EC}=6 ; \mathrm{NCs}=9$

\# $\mathrm{n}=9$ (8 males; 1 female)

${ }^{\# \#} \mathrm{n}=16$ (13 males; 3 females $)$ 
Table 6. Grip Strength and Endurance pre and post each $120 \mathrm{~m}$ climb $(\mathrm{n}=17)$.

\begin{tabular}{|c|c|c|c|c|c|}
\hline \multirow{4}{*}{ Pre Climb $1(\mathrm{~kg})^{+* \wedge}$} & \multicolumn{3}{|c|}{ Grip Strength } & \multicolumn{2}{|c|}{ Grip Endurance } \\
\hline & & \multicolumn{2}{|c|}{ Combined $(\mathrm{EC}+\mathrm{NC})$} & \multicolumn{2}{|c|}{ Combined $(\mathrm{EC}+\mathrm{NC})$} \\
\hline & & Non-dominant & Dominant & Non-dominant & Dominant \\
\hline & Mean & 41.30 & 43.36 & 25.42 & 24.79 \\
\hline & SD & 7.42 & 7.91 & 4.99 & 5.03 \\
\hline & Min & 29.30 & 28.30 & 17.00 & 13.40 \\
\hline & Max & 59.60 & 61.70 & 33.30 & 31.20 \\
\hline \multirow[t]{4}{*}{ Post Climb $1(\mathrm{~kg})$} & Mean & 24.25 & 26.62 & 17.25 & 16.87 \\
\hline & SD & 5.86 & 6.45 & 4.61 & 4.60 \\
\hline & Min & 15.10 & 16.80 & 11.00 & 9.10 \\
\hline & Max & 34.00 & 38.00 & 26.29 & 26.10 \\
\hline \multirow[t]{2}{*}{ Change Climb $1(\mathrm{~kg})$} & Mean & 17.05 & 16.74 & 8.46 & 7.53 \\
\hline & $\mathrm{SD}$ & 5.32 & 5.95 & 4.51 & 5.60 \\
\hline Statistical sig. & & $\mathrm{t}_{(16)}=7.457 ; \mathrm{p}<0.001 ; d=2.55$ & $\mathrm{t}_{(16)}=5.778 ; \mathrm{p}<0.001 ; d=2.32$ & $\mathrm{t}_{(16)}=7.457 ; \mathrm{p}<0.001 ; d=1.70$ & $\mathrm{t}_{(16)}=5.778 ; \mathrm{p}<0.001 ; d=1.64$ \\
\hline \multirow[t]{4}{*}{ Pre Climb $2(\mathrm{~kg})^{*}$} & Mean & 33.71 & 37.16 & 20.94 & 19.99 \\
\hline & SD & 7.62 & 8.51 & 5.77 & 6.00 \\
\hline & Min & 21.30 & 23.60 & 11.50 & 9.50 \\
\hline & Max & 50.60 & 53.80 & 31.90 & 34.00 \\
\hline \multirow[t]{4}{*}{ Post Climb $2(\mathrm{~kg})$} & Mean & 23.66 & 25.98 & 15.84 & 15.18 \\
\hline & SD & 6.68 & 6.72 & 4.31 & 4.01 \\
\hline & Min & 16.70 & 16.50 & 10.10 & 9.50 \\
\hline & Max & 38.70 & 39.90 & 26.70 & 23.50 \\
\hline \multirow[t]{2}{*}{ Change Climb $2(\mathrm{~kg})$} & Mean & 10.04 & 11.18 & 4.51 & 4.77 \\
\hline & SD & 5.24 & 6.07 & 3.45 & 4.02 \\
\hline Statistical sig. & & $\mathrm{t}_{(16)}=5.623 ; \mathrm{p}<0.001 ; d=1.40$ & $\mathrm{t}_{(16)}=4.539 ; \mathrm{p}<0.001 ; d=1.47$ & $\mathrm{t}_{(16)}=5.623 ; \mathrm{p}<0.001 ; d=1.00$ & $\mathrm{t}_{(16)}=4.539 ; \mathrm{p}<0.001 ; d=0.94$ \\
\hline \multirow[t]{4}{*}{ Pre Climb $3(\mathrm{~kg})^{\wedge}$} & Mean & 33.85 & 37.08 & 19.51 & 19.21 \\
\hline & $\mathrm{SD}$ & 6.30 & 7.43 & 5.77 & 4.85 \\
\hline & Min & 22.40 & 24.70 & 11.00 & 10.70 \\
\hline & Max & 46.50 & 51.80 & 32.20 & 27.50 \\
\hline \multirow[t]{4}{*}{ Post Climb $3(\mathrm{~kg})$} & Mean & 22.30 & 24.79 & 15.26 & 14.68 \\
\hline & SD & 6.81 & 6.84 & 4.20 & 3.98 \\
\hline & Min & 14.80 & 15.20 & 9.50 & 7.60 \\
\hline & Max & 36.40 & 39.40 & 22.40 & 21.10 \\
\hline \multirow[t]{2}{*}{ Change Climb $3(\mathrm{~kg})$} & Mean & 12.86 & 13.75 & 4.50 & 4.63 \\
\hline & SD & 7.10 & 9.25 & 5.08 & 4.05 \\
\hline Statistical sig. & & $\mathrm{t}_{(15)}=3.493 ; \mathrm{p}<0.003 ; d=1.76$ & $\mathrm{t}_{(15)}=4.733 ; \mathrm{p}<0.001 ; d=1.72$ & $\mathrm{t}_{(16)}=3.493 ; \mathrm{p}=0.003 ; d=0.84$ & $\mathrm{t}_{(16)}=4.773 ; \mathrm{p}<0.001 ; d=1.02$ \\
\hline
\end{tabular}


Table 7. Mean SD kinematic and kinetic data during each $120 \mathrm{~m}$ climb. $(\mathrm{n}=17 ; \mathrm{EC} \mathrm{n}=7$; Male = 5, Female =2: Novice Climbers $\mathrm{n}=10$; Male $=9$, Female $=1)$.

\begin{tabular}{|c|c|c|c|c|c|c|c|c|c|}
\hline & & & \multicolumn{4}{|c|}{ Kinematic } & \multicolumn{2}{|c|}{ Kinetic } & \multirow[b]{2}{*}{$\begin{array}{l}\text { Calf } \\
(\%)\end{array}$} \\
\hline & & & $\begin{array}{l}\text { Toe Clearance } \\
\text { (m) }\end{array}$ & $\begin{array}{c}\text { Hip ROM } \\
\left({ }^{0}\right)\end{array}$ & $\begin{array}{l}\text { Peak Shoulder } \\
\text { Flexion }\left(^{0}\right)\end{array}$ & $\begin{array}{l}\text { Forearm } \\
(\%)\end{array}$ & $\begin{array}{l}\text { Bicep } \\
(\%)\end{array}$ & $\begin{array}{c}\text { Anterior Deltoid } \\
(\%)\end{array}$ & \\
\hline Climb & $\mathrm{EC}$ & Mean & 0.054 & 59 & 113 & 51 & 48 & 34 & 48 \\
\hline \multirow[t]{3}{*}{1} & $*$ & SD & 0.005 & 5.5 & 8.3 & 5.2 & 4.9 & 4.2 & 7.8 \\
\hline & $\mathrm{NC}$ & Mean & 0.049 & 51 & 122 & 55 & 52 & 46 & 33 \\
\hline & & SD & 0.0037 & 3.8 & 9.2 & 4.8 & 4.65 & 4.2 & 8.5 \\
\hline Climb & $\mathrm{EC}$ & Mean & 0.049 & 56 & 132 & 53 & 48 & 37 & 51 \\
\hline \multirow[t]{3}{*}{2} & & SD & 0.004 & 4.5 & 9.7 & 4.9 & 4.5 & 3.5 & 9.8 \\
\hline & $\mathrm{NC}$ & Mean & 0.047 & 46 & 133 & 68 & 50 & 53 & 38 \\
\hline & & SD & 0.0035 & 3.5 & 10.1 & 5.8 & 4.5 & 4.7 & 8.1 \\
\hline \multirow{4}{*}{$\begin{array}{c}\text { Climb } \\
3\end{array}$} & $\mathrm{EC}$ & Mean & 0.048 & 59 & 134 & 66 & 61 & 47 & 62 \\
\hline & & SD & 0.005 & 4.7 & 9.6 & 9.4 & 9.5 & 8.3 & 9.6 \\
\hline & $\mathrm{NC}$ & Mean & 0.044 & 42 & 138 & 78 & 72 & 66 & 46 \\
\hline & & $\mathrm{SD}$ & 0.0033 & 3.2 & 10.4 & 8.6 & 9.1 & 9.7 & 8.7 \\
\hline
\end{tabular}

The data presented represents a 30 second excerpt from the trial.

${ }^{*}$ This climb was undertaken with the addition of a sea survival suit 


\section{Figures}

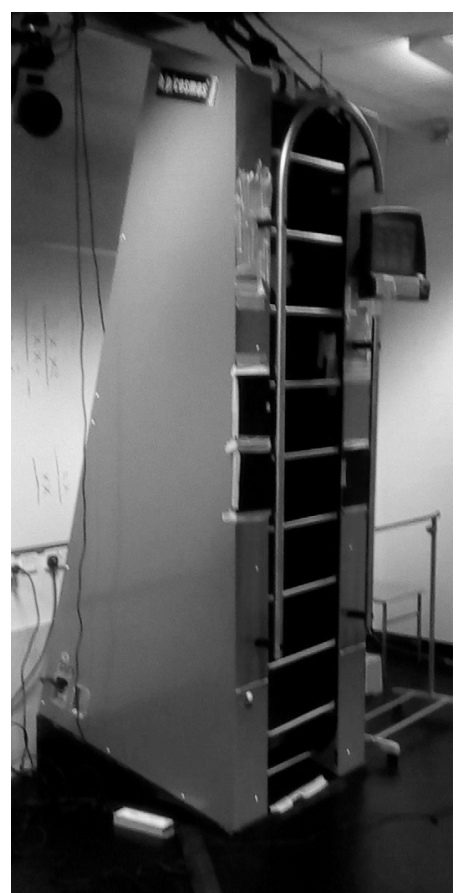

Figure 1. Ladder ergometer. HP Cosmos ladder with wedge underneath to create a vertical ladder treadmill. 


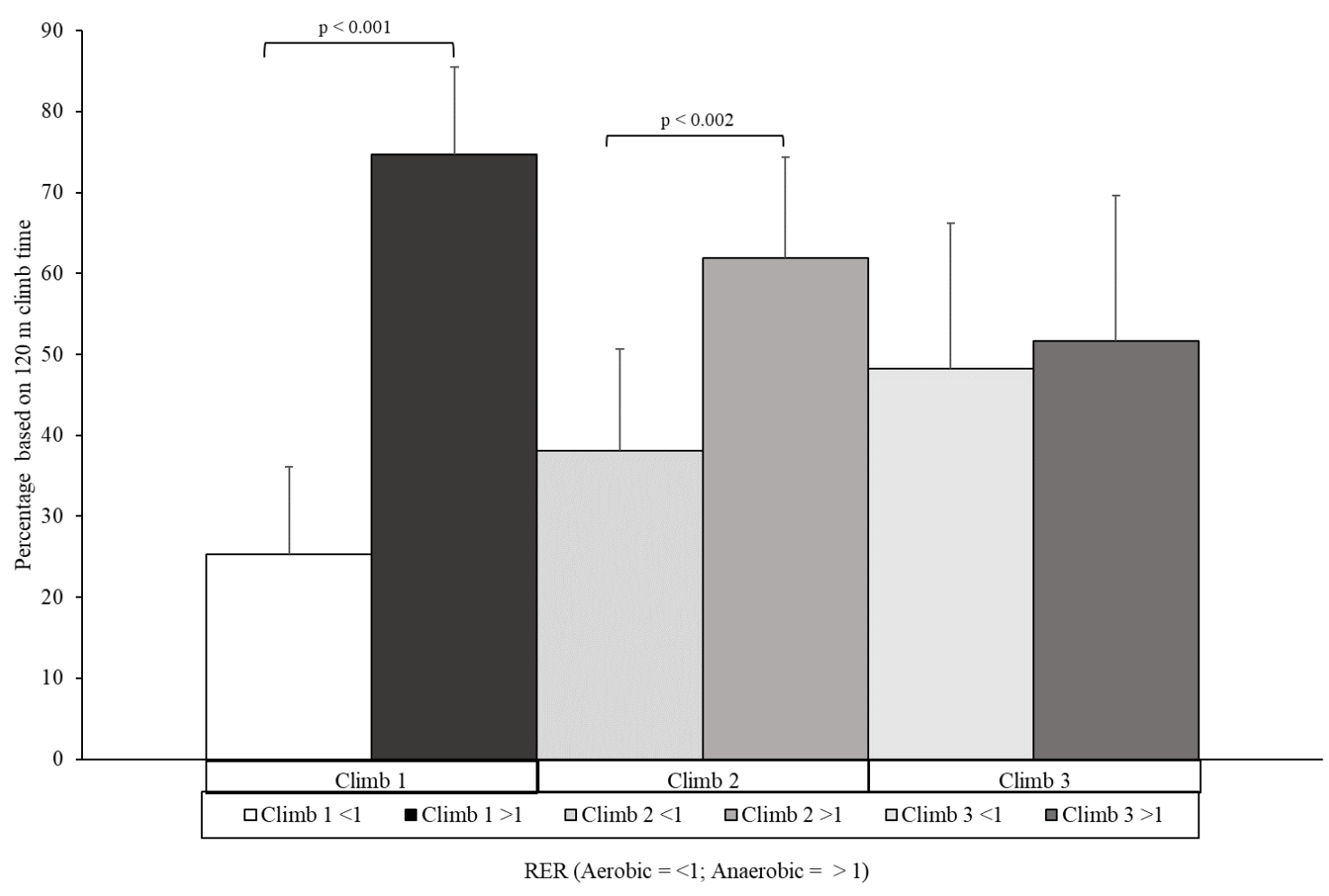

Figure 2. Mean (SD) Percentage of total time spent metabolising energy aerobically and anaerobically (Climb $1 \mathrm{n}=15[\mathrm{EC}=6 ; \mathrm{NC}=9] ;$ Climb 2, $\mathrm{n}=15[\mathrm{EC}=6 ; \mathrm{NC}=9]$ : Climb $3 \mathrm{n}=14[\mathrm{EC}=5 ; \mathrm{NC}=9])$. $N B$. Data could not be computed for one EC due to removal of the facemask between each $30 \mathrm{~m}$ climb. 